Área Abierta. Revista de comunicación

audiovisual y publicitaria

ISSN: 1578-8393

\title{
El Radiosketch en España. De la narrativa tradicional a la participación de las audiencias
}

\author{
Pedro Javier Gómez Martínez; Pablo Garrido Pintado²
}

Recibido: 28 de abril de 2016 / Aceptado: 10 de noviembre de 2016

Resumen. En este artículo se exponen los resultados de un análisis realizado sobre más de un centenar de sketches radiofónicos con la finalidad de extraer algunas consecuencias sobre la evolución de este formato y su papel actual en la comunicación radiofónica. Los materiales analizados proceden de dos importantes cadenas de ámbito nacional y de una plataforma de contenidos en formato podcast. Los objetivos principales del estudio fueron delimitar las actuales fórmulas del formato radiosketch, su evolución y su tendencia; así como comprender su relación con los hechos de actualidad para establecer finalmente algunas claves funcionales de su comunicación. Se utilizaron metodologías cuantitativas para la clasificación de los contenidos encontrados y metodologías descriptivas basadas en el análisis textual para definir sus claves narrativas. El estudio se focaliza en la relación crítica entre el contenido del sketch y la realidad aludida que se satiriza en él. Según los resultados obtenidos, se detectan nuevas fórmulas de aproximación a los valores de las audiencias a través del sketch, mediante el forzado de la fórmula tradicional de guión cerrado con personajes y diálogos definidos, y su sustitución por la fórmula de guión abierto, donde el humorista plantea una situación insólita y favorece su evolución impredecible y en muchos casos extrema. Se analiza la relación entre los sketches que utilizan la imagen pública de celebridades de la vida política, los que aluden a celebridades de otros ámbitos y los que se centran en la descripción de estereotipos sociales para, finalmente, valorar los aspectos críticos de la realidad que en cada uno de ellos se propone.

Palabras clave: Radiosketch, narrativa, radio, comedia radiofónica

\section{[en] The Radio Skit in Spain. Traditional Narrative and Audience Participation}

\begin{abstract}
This article focuses on the results of an analysis conducted on more than one hundred radio skits in order to draw some conclusions about the evolution of this format and its current role in radio communication. For this purpose, we have selected specific documentation of two of the major national radio broadcasters and a platform podcast. The main points of this work are to define the skit radio structure, its evolution, and trends understanding the social context to establish some communication functional keys. Quantitative methodologies for the classification of the levels and descriptive methodologies based on textual analysis to define their narratives keys were used. The study focuses on the critical relationship between the content of the skit and the reality described in it. According to the results, new ways of approaching to the values of the audience through the radio skit are detected, by forcing the traditional formula of closed characters and defined dialogs and replacing the formula for the open script, in which the humorist poses an unusual situation and favors its unpredictable and in
\end{abstract}

1 Universidad Francisco de Vitoria (España)

E-mail: e.gomez.prof@ufv.es

2 Universidad Francisco de Vitoria (España)

E-mail: p.garrido.prof@ufv.es 
many cases extreme evolution. The relationship between skits using the public image of celebrities from political life is analyzed, which allude to celebrities from other fields and focusing on the description of social stereotypes to finally assess critical aspects of reality in each it is proposed.

Keywords: Radio skit, Storytelling, Radio, Radio comedy

Sumario. Introducción 1. Objetivos y metodología. 2. Naturaleza del objeto de estudio. 3. Datos y discusión. 4. Conclusiones. 5. Bibliografía.

Cómo citar: Gómez Martínez, P. J. y Garrido Pintado, P. (2017) El Radiosketch en España. De la narrativa tradicional a la participación de las audiencias, en Área Abierta. Revista de comunicación audiovisual y publicitaria 17 (1), 57-71. http://dx.doi.org/10.5209/ARAB.52476

\section{Introducción}

Casi desde sus orígenes, la radio descubrió su vocación como vehículo de entretenimiento. Entre los géneros radiofónicos, con la hegemonía innegable de los informativos, los de la ficción ocupan un lugar algo restringido aunque, a nuestro entender, privilegiado en lo que toca al enjuiciamiento de la realidad y, por tanto, al posible influjo sobre la percepción de ésta. Su dificultad técnica, principal freno a su expansión, estriba en el hecho de que sea necesaria la concurrencia de actores y la introducción de variados efectos de sonido. Sin embargo, entre estos programas de ficción, el radiosketch destaca precisamente por su sencillez y fácil producción. A menudo considerado obra menor, entre los espacios de ficción de la radio, el sketch sobrevive a numerosos cambios de tendencia en la programación. Como nos recuerdan Emma Rodero y Xosé Soengas:

\footnotetext{
Un sketch es una pieza breve e independiente adaptada a la radio, normalmente con carácter humorístico o sarcástico. Se trata de una palabra inglesa, de difícil traducción, que alude precisamente a la idea de boceto, de esquema. Por tanto, el género presenta una estructura sencilla y un tratamiento formal poco elaborado, sustentado en el estilo expresivo del monólogo o el diálogo entre dos o más personajes. [...] Un ejemplo, ya histórico en la radio, fue la creación del personaje del señor Casamajor, pero existen otros muchos ejemplos como los diálogos en tono burlesco, en los comienzos de la radio del primer locutor de Radio Nacional de España, Fernando Fernández de Córdoba, en el programa Miliciano Remigio, pa la guerra un prodigio, pasando por Pepe Iglesias el Zorro o Tip y Top, hasta los más recientes, de la mano de Gomaespuma, Alfonso Arús o Buenafuente (2010: 70).
}

A su brevedad, el radiosketch añade, entre sus más significativas señas de identidad, «una estructura simple y una fundamentación formal basada en la fuerza del diálogo como principal herramienta» (López, 2014). A pesar de presentar una estructura cerrada, con principio, medio y fin, acostumbra a integrarse en programas magacín, siguiendo una tendencia que se remonta a los orígenes mismos de esta clase de programa, en los años de la posguerra (Bustos Sánchez, 2003: 212). Sigue siendo aún hoy, si se quiere, un contenido complementario que alivia la tensión informativa de las primeras horas de la mañana (Martínez Costa, 2004), en la transición desde la información hacia el entretenimiento.

Este estudio reflexiona sobre el papel vindicativo del sketch y sobre su capacidad para generar distanciamiento con la realidad que propone la noticia. Para la realización de este trabajo, se han analizado numerosos casos de radiosketches difundidos a través 
de ondas y de la red, en formato podcast, con el objetivo de valorar su sentido y de discutir su función comunicativa respecto a las audiencias.

\section{Objetivos y metodología}

Los objetivos de este estudio son:

1. Encontrar rasgos distintivos de tendencia en los sketches radiofónicos actuales que permitan vislumbrar su tipología y, en su caso, evolución.

2. Detectar la presencia de la actualidad analizando los recursos utilizados para crear humor y la deformación que sobre la realidad provocan tales recursos.

3. Delimitar su función en el contexto de la dimensión comunicativa de la estación radiofónica o página web estableciendo qué le podría aportar el contenido humorístico a la noticia y generando una reflexión en torno a sus posibles consecuencias.

\subsection{Muestra}

En definitiva, queríamos saber cómo son, cómo tratan la realidad, para finalmente discutir cuál podría ser su intención respecto a ésta. Tomamos como base los principales programas de ámbito nacional emitidos en Radio Nacional de España (radio pública de ámbito nacional) y Cadena SER (radio más escuchada, según el EGM, de los últimos 20 años), entre el 1 de enero y el 31 de marzo de 2016, en horario de 6:00 a 12:00, de lunes a domingo, así como otros elegidos por su trascendencia, como el podcast de descarga libre del dúo cómico Gomaespuma denominado Podcast con orejas - compuesto, en líneas generales, de extractos de su programa en M80 Radio y correspondientes a un periodo de observación más amplio y emitidos en horario de tarde.

Aunque no se trata de un estudio sobre el impacto, consideramos importante centrar el análisis en sketches con difusión amplia y, dado el creciente consumo de estos contenidos por Internet, obtuvimos parte de la muestra en la red. Ya a finales del siglo XX se intuía la importancia de este medio en el ámbito de la radio. «Las cadenas españolas han rivalizado por incluir sus programas en la red Internet, que al inicio de la temporada 96/97 era consultada habitualmente por unos 700000 españoles» (Checa, 1997: 29). Hoy se sabe que, por ejemplo, los jóvenes nativos digitales recurren a la red como medio preferente para buscar información y entretenimiento (Catalina-García, García y Montes, 2015: 616) y que más del $76 \%$ de la población consume diariamente información por esa vía, según datos disponibles de este mismo año (EGM, 2016). En lo que respecta a la radio el consumo online se realiza mediante la práctica del simulcasting (emisión simultánea en directo por ambas vías) y del podcasting (archivos disponibles a la carta en red con posibilidad de suscripción, normalmente gratuita, a través de feed RSS). Hoy, tanto la radio por Internet como la redifusión indirecta a través de podcast en portales y páginas que no están controladas por las emisoras, resulta una realidad innegable que no podemos dejar de tener en cuenta.

Considerar los sketches de radio difundidos a través de la red, nos servía para no dar la espalda a la creciente expansión por esta vía y, en su caso, para comprobar si se daban sensibles diferencias de contenido entre un canal y otro. Finalmente, se 
comprobó que no sucedía. También nos permitió incluir en la muestra el caso de un sketch emitido en una emisora local y que, sin embargo, alcanzó una difusión muy elevada a nivel nacional. Se trataría de lo que hemos querido denominar un falso sketch, descargado y difundido por numerosos medios de ámbito nacional. Hablamos de la falsa llamada del President Puigdemont al Presidente Rajoy radiada el 20 de enero de 2016. En este caso, además, hicimos un seguimiento de su impacto en prensa.

Con el material seleccionado, realizamos una división de contenidos. Aplicamos una metodología cuantitativa para delimitar la presencia o ausencia de temas noticiosos frente a otros con menor representación en los titulares de noticias. Posteriormente, se distinguió entre el tipo de actualidad que resultaba referida para, después, realizar un análisis textual centrado en los recursos utilizados por los locutores y humoristas que afectaban a la narrativa del sketch.

\subsection{Herramientas de análisis}

La ficha de análisis utilizada reunía los siguientes datos:

Cadena/Fuente

Fecha y hora

Duración

Temática (indicar)

Título/careta específica: SI/NO (en su caso, indicar cuál)

Participación audiencia: SI/NO

Plano del Contenido:

Alude a temáticas de actualidad (totalmente/parcialmente/puntualmente)

Alude a personajes y situaciones relacionadas con la política: SI/NO

Alude a personajes y situaciones relacionadas con la actualidad/realidad:

$\mathrm{SI} / \mathrm{NO}$

Alude a personajes y situaciones del mundo del deporte: SI/NO

Alude a personajes y situaciones del mundo del espectáculo: SI/NO

Alude a personajes y situaciones de otros ámbitos de la actualidad/ realidad: SI/NO

Plano de la expresión:

Enunciador reconocible

Utiliza narrador

Participa la audiencia

Participa invitado

Rasgos asociados a personajes:

Principal

Secundarios

Figuras retóricas identificadas

Recursos humorísticos utilizados 
En cada ficha se añadió un espacio para observaciones. Para la definición de las funciones comunicativas se recurrió a un grupo de discusión de siete expertos, todos ellos profesores de Comunicación y estudiantes de Doctorado.

\section{Naturaleza del objeto de estudio}

Encontramos una carencia de estudios académicos que versen sobre el sketch radiofónico. En una ficción humilde y poco valorada, tras la aparente desinhibición del humor, a menudo subyace una crítica más corrosiva que expresa una mayor voluntad de cambio, lo que viene a demostrar una vez más que no hay formatos menores. Martín Rojo (2007: 600) se refiere a las implicaciones del humor en los grandes temas, como iniciadores de lo que la autora denomina «procesos deslegitimadores», en el sentido de que la noticia legitima o deslegitima los hechos reales, pero el humor tiende a poner énfasis en lo más criticable y deplorable de la realidad, ya que mediante la ridiculización de algo o alguien se suele cuestionar la seriedad del argumento.

\subsection{Principales diferencias narrativas con otros formatos de ficción radiofónica}

Podríamos sintetizar su singularidad en algunas diferencias narrativas respecto a otros formatos de ficción radiofónica:

\subsubsection{Naturaleza del enunciador}

En primer lugar nos interrogamos por la propia naturaleza del enunciador. A diferencia de los otros formatos de ficción en radio, el radiosketch evita la presencia de actores y en su lugar tiende a utilizar las voces de presentadores, locutores y animadores de programas - quienes se desdoblan en actor y personaje añadiendo una componente de espectacularidad a la naturaleza del espacio en el que actúan-, lo que a su vez permite, como sólo sucede en otro género ficcional, la «recreación» (Guarinos, 2009: 249), el lucimiento de locutores y presentadores con inquietud por la interpretación. Se trata de interpretaciones nítidas, elementales, con personajes que tienden al estereotipo. Cuando en el sketch se producen alusiones a personajes conocidos, resulta particularmente interesante la capacidad mimética de algunas voces con respecto al timbre de celebridades bien conocidas por los oyentes. Como señalara García García, en los momentos en los que el locutor se mantiene ajeno a este juego de identidades, subsiste en su relación con el escuchante una representación mental basada en la singularidad de su voz:

Cada voz singulariza a su fuente, la convierte en única. Las señales vocales (tono, timbre, intensidad, velocidad, elocución, originalidad) son como las huellas dactilares, irrepetibles en su conjunto, y a su vez sirven para identificar a los hablantes (García García, 1997: 45).

Y como nos describe más adelante este mismo autor, esa representación que el escuchante modela, termina estableciendo un vínculo de naturaleza afectiva. En el radiosketch se sacrifica la identidad del enunciador en favor de los personajes 
aludidos. La voz familiar se transmuta, a veces con el apoyo de la técnica, en otra igualmente reconocible y no menos familiar - la de la celebridad imitada - , casi siempre con plena conciencia por el escuchante de esa doble identidad. De forma inevitable, el contenido crítico que pueda haber en el mensaje se asocia al punto de vista del locutor, aunque cabe una segunda posibilidad, la que introduce la incertidumbre del escuchante que se incorpora a la emisión por primera vez y en medio de ella, ajeno por completo a la broma, y que puede llegar a interpretar con estupor que la voz que está escuchando es en realidad la verdadera voz del personaje imitado. Así ocurre la mayoría de las veces. Esta confusión entre ficción y realidad no es nueva históricamente hablando, y sus ancestros podrían remontarse hasta la emisión del ya mítico programa de Orson Welles La guerra de los mundos, en el que se describía con cierta ambigüedad una supuesta invasión marciana (Albert y Tudesq, 1981: 42). Cierto es que el programa abundaba en cortinillas que recordaban a la audiencia que se trataba de un radioteatro algo atípico, pero los momentos en los que no era así, gran parte de la audiencia tomó partido por aceptar la ficción como una realidad.

Lo que diferencia hoy al enunciador del sketch del de otros programas radiofónicos de ficción sería su doble naturaleza de animador/actor y la posibilidad de reconocimiento o no por parte del escuchante, así como los distintos sentidos que ambas posibilidades podrían introducir.

\subsubsection{Los planos sonoros}

Un segundo aspecto narrativo se refiere a los planos sonoros: primero, normal, general o de fondo (Díez Puertas, 2003: 282). El radioketch simplifica por lo general al máximo el tratamiento del sonido, cuya manifestación en capas sólo es perceptible para el escuchante cuando se añaden efectos de ambiente. El propio espíritu de improvisación elude una producción más cuidada en este sentido, tal vez porque le restaría algo de autenticidad, pero muy posiblemente también porque su ejecución, casi siempre en directo, se complicaría bastante. Se utilizan algunos efectos de sonido, pero en general, pocos.

\subsubsection{Narrador}

El tercer aspecto tiene que ver con la escasa presencia de narradores en general, y de los extradiegéticos en particular, aquellos que cuentan la historia al escuchante sin relacionarse con los personajes. Algunas excepciones se obtienen respecto a los narradores que además son personajes y participan de la narración (intradiegéticos/ homodiegéticos), es decir, cuando por ejemplo se simula un contexto periodístico en el que el imitador de un periodista describe lo que está contando como lo haría aquel en un programa real. En la muestra analizada, la mayor parte de las veces los hechos transcurren sin que una voz se ocupe de relatarlos de una manera explícita. Prevalecería como última instancia narrativa, algo similar al meganarrador cinematográfico, la mente que en última instancia ha creado el artificio, el relato, y lo conduce por donde más le conviene, sin huellas en la diégesis. 


\subsubsection{El diálogo improvisado}

En cuarto lugar, nos encontramos otro elemento mucho menos apreciable, aunque pueda darse en el sketch televisivo, y es el alto grado de improvisación en los diálogos. Si lo que cabría esperar en el diálogo de cualquier otra ficción narrativa es su precisión, de modo que el guionista «trabaje los tonos de los parlamentos» (Díez Puertas, 2003: 282), en el radiosketch el diálogo admite un margen de improvisación muchísimo mayor, dándose los siguientes escenarios:

a) No hay diálogo, sólo situación sobre la que las voces improvisan.

b) Es un diálogo indicado, no escrito (se expresa lo que se dice, pero no el cómo).

c) Es un diálogo escrito, pero al que se le hacen añadidos y en el que se incluyen toda clase de digresiones, algunas de las cuales llegan a provocar desconcierto en las propias voces actuantes, lo que se subraya con su risa sin la menor ocultación.

\subsection{Relación con la realidad y el hecho noticioso}

Como ya adelantábamos, nuestra pretensión quería incidir en el modo en el que el sketch de radio se relaciona con la realidad que expresa.

Las realidades sociales, por ende, son interpretaciones del universo simbólico que se traducen en un discurso verosímil de lo que el tejido social representa sobre sí, y representa sobre lo que desea que se interprete de sí (Estupiñan, 2010:35).

Partimos de la experiencia acumulada en otro trabajo anterior (Gómez y Casal, 2015) donde dábamos cuenta de la responsabilidad del falso documental en la percepción fallida de la realidad. Lo que aquí defendemos es que, de algún modo, ciertas prácticas del radiosketch más contemporáneo flirtean con la realidad llevando en ocasiones al equívoco, de modo que no faltan momentos en donde el oyente duda respecto a si lo que escucha es una deformación o la realidad misma. En ese sentido, estaríamos hablando de un tipo de «radiorrealidad» (Álvarez, 2005), en continuidad directa con la experiencia de Welles antes mencionada. Se observó que el contenido de los sketches admitía la siguiente variedad, que muestra cuatro niveles de conexión con la realidad:

a) Situaciones inventadas no directamente relacionadas con ninguna noticia.

b) Situaciones inventadas indirectamente relacionadas con la noticia.

c) Situaciones inventadas directamente relacionadas con la noticia.

d) Situaciones extraídas de alguna noticia pero «ficcionalizadas».

A continuación explicamos los rasgos distintivos entre las categorías b y c. En ocasiones, unas declaraciones desafortunadas de un determinado personaje - por ejemplo, las declaraciones de la política española María Dolores de Cospedal sobre el «despido en diferido» del tesorero del Partido Popular (PP), Luis Bárcenaspueden generar verdaderas oleadas de contenido satírico y humorístico, donde el 
radiosketch se desenvuelve en su medio natural. Distinguimos que en unos casos el sketch reproducía la situación real, exagerando el hecho o introduciendo variantes, mientras que en otros casos se aprovechaba del conocimiento previo del hecho por el escuchante, para bromear respecto a otro asunto (alusiones en otros sketches al confuso término creado por María Dolores de Cospedal).

Naturalmente, la realidad puede abarcar ámbitos muy diversos aunque nos interesaron de manera especial las temáticas intrínsecamente relacionadas con las noticias del espectro político. Por ello distinguimos entre:

a) Realidad política

b) Realidad no política:

i) Realidad deportiva

ii) Realidad del espectáculo

iii) Otras

Las tres subcategorías de la realidad no política abarcan un número significativo de casos. Obviaremos, por el momento, los datos referentes a los porcentajes por entender que la muestra (apenas un centenar de sketches analizados) no puede ser representativa más que en términos de tendencia. Pero en ese mismo sentido, diremos que la realidad política en un periodo de crisis, no resultaba la más aludida y su incidencia caía por debajo del $32 \%$ de casos. Insistimos en la irrelevancia del dato numérico, nos basta con asegurar que en el rastreo era visible que estos contenidos no resultaron, como creímos en un principio, mayoritarios.

En los casos en los que la realidad política resultaba aludida de manera directa o indirecta, el posicionamiento de los humoristas era siempre crítico, buscando incidir en los aspectos más ridículos en los que el personaje se hubiese visto comprometido. En algunos casos, se apreció que el sketch a veces también enjuiciaba la actitud sistemáticamente crítica y desconfiada de la ciudadanía. Sirva como ejemplo una pieza del dúo Gomaespuma en el que se produce la llamada de un falso escuchante para repetir sistemáticamente que está en contra de todo y que «todo es un asco». En definitiva, es una parodia de la audiencia general, que es capaz de reírse de sí misma. Se diría que la intención metadiscursiva del humor aquí no es otra que reírse del espíritu crítico en un ejercicio de humildad que contrasta con la sed de reprobación hacia los políticos. De hecho, si considerásemos que los numerosos sketches referidos a los hábitos, costumbres y vicios de la ciudadanía ocupan cuando menos el mismo espacio que aquellos otros referidos a la política, llegaríamos a la conclusión de que esta forma de humor responde a necesidades bien distintas:

1) Aliviar las consecuencias dramáticas de los errores políticos exorcizando el dolor con humor, en este sentido, un uso catártico del humor bien conocido desde los tiempos de Freud (Villacañas, 2003).

2) Hacernos tomar conciencia de nuestros defectos. 


\subsection{El radiosketch frente a la realidad de la noticia}

La realidad y el medio han sido confrontados y estudiados desde muy diferentes perspectivas y teorías. Siguiendo al filósofo Gustavo Bueno, existen tres ámbitos de relación entre la realidad y el medio televisivo. Si algo no está en el mundo, no estará en el medio («Teoría de la dictadura de la audiencia»); lo que está en el medio, está porque está en el mundo («Teoría ingenua»); finalmente, cabe la posibilidad de que lo que el medio muestre sea simplemente apariencia, engaño o mentira («Teoría crítica») (Bueno, 2000: 60-65). Aunque Bueno se refería predominantemente a la televisión, aplicamos estos postulados a cualquier medio masivo y en especial al radiofónico, merced al proceso de convergencia intermedial (Salaverría: 2003). El radiosketch, desde la perspectiva de la «Teoría de la dictadura de la audiencia», es una consecuencia lógica de lo que el público pide, es decir, es una crítica pero también un alivio al dramatismo de lo cotidiano. En este sentido, por tanto, hablaríamos de un género evasivo.

Desde la perspectiva de la «Teoría ingenua de la televisión», las exageraciones y aberraciones de la realidad sugeridas en el sketch, contribuyen a que veamos una realidad sesgada que desde un punto de vista objetivo no existe, pero a nuestro entender, esta exageración podría implicar varios efectos muy contradictorios. Por un lado, aumentar la desconfianza hacia figuras públicas - lo que podría hacernos más críticos-, pero por otro, justamente todo lo contrario, insensibilizar ante sus errores ya que se han tomado como bromas. En este sentido, conllevaría a una pérdida en la capacidad de reacción de las audiencias frente a la realidad criticada al relativizar con el humor una parte sustancialmente importante del dolor que la realidad produce. Hablaríamos entonces de un género a mitad de camino entre lo evasivo y lo vindicativo.

Finalmente, desde la «Teoría crítica» estos sketches son una «mentira más» que nos aleja de la realidad. Por tanto, no se deberían tomar muy en serio, ya que se trata de humor, los hechos transmitidos ni el sentido que producen o intentan producir (crítica, rechazo). Estaríamos, de nuevo, ante un modelo evasivo.

Hasta aquí, la evolución de este formato parecía clara: cuando alude a la realidad, mantiene una distancia con ella que es evidente para las audiencias y que juega en favor de la evasión. Se observó sin embargo, que a la retórica de la deformación, tan frecuente en los programas de humor, le surgía un competidor: la ambigüedad, otra figura retórica que en este caso, en vez de evidenciar la distancia con lo real, promueve la duda, hace que el escuchante se plantee si realmente lo que escucha es un sketch o es real.

Fueron numerosos los casos en los que se alentaba esta posibilidad, pero la muestra obtenida por la plataforma de podcast, nos permitió analizar un caso de particular interés por su repercusión mediática en las fechas del muestreo, emitido en principio en una estación local, pero que terminó alcanzando difusión de ámbito nacional. Nos referimos a la falsa llamada del President de la Generalitat al Presidente del Gobierno. ¿Cuál fue el verdadero efecto de esa broma, para muchos, de mal gusto? Para eso rastreamos a continuación el eco que el hecho produjo en la prensa escrita $\mathrm{y}$ en la radio.

En el periódico digital eldiario.es concluye la voluntad de diálogo de Rajoy (Puente, 2016), lo que parece beneficiar a Rajoy. El seguimiento de la noticia que hizo la cadena SER (Cadena Ser, 2016) destacó la facilidad con la que el locutor 
local Marc Casanova, de Ràdio Flaixbac, consiguió acceder al Presidente del Gobierno, valorando la competencia del personal de Presidencia. A su vez, destaca en las palabras del director del programa, Carles Pérez, lo que éste definió como el buen fair play de Rajoy: de nuevo, un comentario positivo respecto a Rajoy.

En el diario El País, tras una descripción de los hechos y la transcripción del diálogo entre Rajoy y el falso Puigdemont, informa que «Rajoy no ha hablado todavía con Puigdemont, pero el Presidente catalán ya sabe qué le podría haber dicho. El mismo programa intentó hablar ayer con la Generalitat haciéndose pasar por Rajoy, pero el intento fracasó» (Roger, 2016): por tercera vez, Rajoy, presunta víctima, sale beneficiado. En la edición digital de El Mundo se realiza una descripción muy similar pero se añaden las críticas de los partidos políticos Ciudadanos (C's) y Partido Socialista Obrero Español (PSOE) respecto a «que se banalice la relación entre el Gobierno y la Generalitat» (Europa Press, 2016). En cualquier caso, esta información sigue beneficiando a Rajoy.

Por su parte, ABC recuerda que ya hubo otros casos anteriores como los de los presidentes Hugo Chávez, Evo Morales y Juan Manuel Santos, víctimas también de la misma clase de broma (ABC.es, 2016). El Periódico recalca las palabras de Rajoy respecto a la «agenda muy libre» que el Presidente dijo tener (El Periódico, 2016). Tal vez este enfoque fuera el más crítico con respecto al líder aludido. Finalmente, La Vanguardia destaca el tono distendido de Rajoy al expresarse con la frase «President, ¿cómo va la vida?» (La Vanguardia, 2016). En nuestra opinión, una imagen cercana y humana con la que no se le suele identificar.

A juzgar por los titulares de la prensa, concluimos que un Presidente del Gobierno al que se ha acusado de eludir el diálogo, tiende la mano en un tono cercano a Puigdemont. Posiblemente, la broma sólo pretendía dar contenido, de manera fácil y amena, a la programación de tarde de una emisora local. El resultado, además de humorístico, cambia sensiblemente la percepción tensa del problema aludido: la cuestión catalana.

En lo que respecta al radiosketch contemporáneo, esta clase de bromas cabría perfectamente dentro del sketch de imitación, como una variante que lo pone en contacto con la realidad y que, sin duda, genera efectos respecto a ella. Esta misma fórmula se diferencia del sketch tradicional en la imposibilidad, al menos aparente, de definir el desenlace de antemano. También es posible detectar un parentesco con las bromas de cámara oculta, definidas por Izquierdo como «una variante documental de las bromas ordinarias» (Izquierdo, 2006: 103). Aunque en este caso no se dé la condición de respetar la autorización del sujeto a posteriori, ni su anonimato.

\section{Datos y discusión}

Como podemos apreciar en la tabla 1, la mayor parte de los radiosketches abundan en hechos cotidianos que guardan alguna relación con la realidad, ya se trate de sucesos noticiables o no, y estén o no relacionados con la política. Del reconocimiento que la audiencia hace de la situación planteada estriba en buena parte el éxito o el fracaso de la acción comunicativa que se produce cuando entendemos el punto de vista del humorista. La mejor prueba de esto último es el caso de la falsa llamada analizada. Aquí el radiosketch, más que describir la realidad bajo una cierta 
caricatura, busca provocarla. En términos generales, sabremos cómo comienza, pero no cómo termina (salvo que haya complicidad en la otra parte y esto se le oculte al público). Es un experimento de laboratorio abierto a múltiples desenlaces. Pero como ya hemos dicho, igual que se diseña una broma, se puede diseñar una falsa broma. Respecto de esta última, el debate se establecería en torno a si se puede utilizar al personaje como cómplice, a cambio de proporcionarle una imagen pública que le beneficie.

Casi todos los sketches analizados giraban en torno a lo esperpéntico. Los contenidos de impacto político no fueron los más frecuentes. Aquí es de destacar el enorme peso de las figuras del deporte y del espectáculo, por ese orden. Igual que en el caso de los políticos, estos personajes recibían un juicio siempre era desfavorable. Observamos también que muchas veces los personajes no eran celebridades de la vida política o deportiva, sino estereotipos de la vida cotidiana como la persona que se cuela en el supermercado, la que se arrima a los famosos por sistema o la que no se entera de nada.

En la siguiente tabla 1 y gráfico 1 mostramos los datos relativos a los radiosketches estudiados en este artículo.

\begin{tabular}{|l|c|c|}
\hline \multicolumn{1}{|c|}{ Tema aludido en el sketch } & Frecuencias & Porcentajes \\
\hline Radiosketches de realidad política (RSRP) & 37 & $31,89 \%$ \\
\hline Realidad deportiva (RD) & 35 & $30,17 \%$ \\
\hline Realidad del espectáculo (RE) & 19 & $16,37 \%$ \\
\hline Otras & 25 & $21,55 \%$ \\
\hline Total sketches analizados & 116 & $100 \%$ \\
\hline
\end{tabular}

Tabla. 1. Frecuencias por tipo de realidad aludida. Elaboración propia.

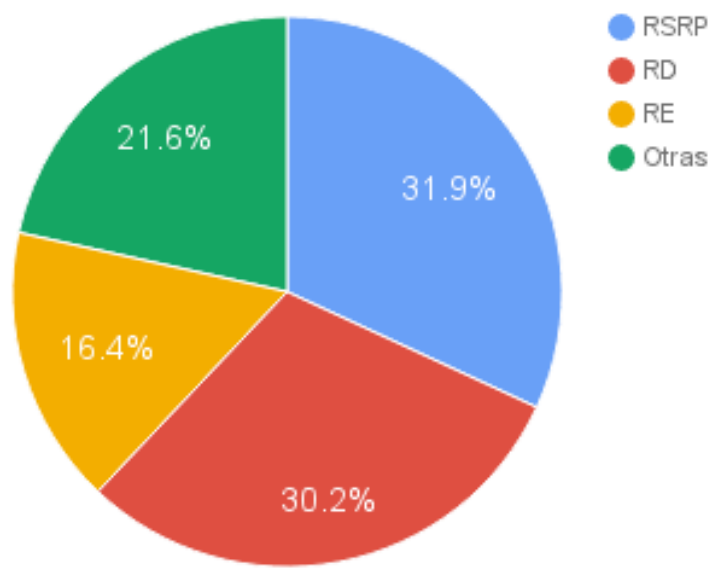

Figura. 1. Frecuencias por tipo de realidad aludida. Elaboración propia. 
No parece que la situación general de descontento monopolice el formato, aunque la presencia de esta clase de contenidos es bastante alta. Prima el entretenimiento sobre la vindicación y la crítica a la realidad. Detectamos dos funciones principales: la de indisponernos hacia alguien o hacia algo - que denominamos función críticay la que cabe deducir del propio resultado humorístico del sketch. Nos pareció aquí que la función del radiosketch sería la de distanciamiento con respecto a la realidad para provocar alguna clase de mejora en el estado de ánimo. El humor suaviza nuestras preocupaciones y, en ese sentido, las hace menos intensas. En la tabla 2 y gráfico 2 se reflejan los datos relativos a las situaciones representadas en los radiosketches aludidos.

\begin{tabular}{|l|c|c|}
\hline \multicolumn{1}{|c|}{ Situaciones Representadas } & Frecuencias & Porcentajes \\
\hline $\begin{array}{l}\text { Situaciones inventadas, no directamente } \\
\text { relacionadas con ninguna noticia }\end{array}$ & 25 & $21,55 \%$ \\
\hline $\begin{array}{l}\text { Situaciones inventadas indirectamente } \\
\text { relacionadas con la noticia }\end{array}$ & 63 & $54,31 \%$ \\
\hline $\begin{array}{l}\text { Situaciones inventadas directamente } \\
\text { relacionadas con la noticia }\end{array}$ & 11 & $9,48 \%$ \\
\hline $\begin{array}{l}\text { Situaciones extraídas de alguna noticia, } \\
\text { pero «ficcionalizadas» }\end{array}$ & 17 & $14,65 \%$ \\
\hline Total situaciones mostradas & 116 & $100 \%$ \\
\hline
\end{tabular}

Tabla. 2. Tipo de situación representada.

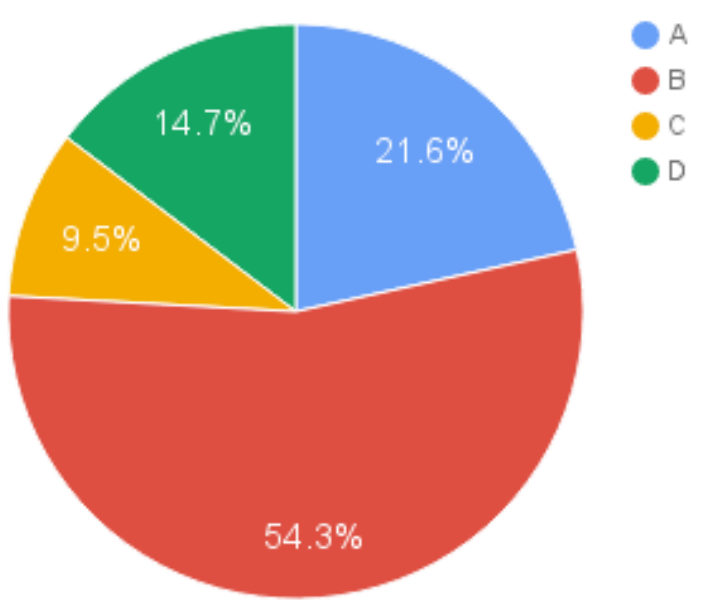

Figura. 2. Situaciones representadas. Elaboración propia. 
Finalmente y en lo que respecta a la tendencia, observamos la señalada hibridación del sketch hacia la radiorrealidad en los sketches de falsa llamada telefónica, donde no sólo se pone a prueba al personaje - que no es necesariamente siempre una celebridad, puede ser el anónimo operador de un servicio de información-, sino que también el humorista acepta el riesgo del resultado de la broma.

Los radiosketches de la muestra estudiada, en los que se utilizaba la imagen pública de celebridades de la vida política, se caracterizaban en su mayoría por la diversidad de contenidos (mítines electorales, debates, ruedas de prensa o escenas de intimidad) sin que prevaleciera con claridad ninguna situación concreta. En general, la situación solía tener mucho más que ver con sucesos concretos de la realidad en los que se inspiraban.

Los radiosketches que aludían a celebridades de otros ámbitos se caracterizaban por situaciones repetidas en función del personaje de que se tratara (por ejemplo, futbolistas entrevistados en el campo, entrenadores en ruedas de prensa o actrices en programas de famosos). Se comprobó la emergencia de un nuevo tipo de sketch que podríamos denominar sketch integrado, cuando se incorpora a una retransmisión la figura del imitador cuyos comentarios aluden a lo que habría podido decir, satirizando siempre a un personaje.

Por último, los que se centraban en la descripción de estereotipos sociales redundaban en personajes de cierta carencia intelectual, con atributos de clase exagerados (del pijo al macarra) y, por lo general, tendentes al estereotipo del pícaro (tramposos o ladrones).

\section{Conclusiones}

El sketch se ha instalado, en las últimas décadas, de manera especial en los programas de información general, como una estrategia discursiva que tiende a suavizar la dureza de los contenidos procedentes de la información diaria. Su presencia en las últimas horas de la mañana y primeras de la tarde, cuando los contenidos persiguen más el entretenimiento que la información, así lo corrobora.

Los actuales momentos de crisis, en los que la actualidad impacta sobre las audiencias de manera permanente, no generan a largo plazo, un incremento en el número, ni en el contenido crítico de los sketches de denuncia o de vindicación de la muestra analizada, aunque sí se observa mayor incidencia en los días más próximos al hecho noticioso.

La función de entretenimiento predomina en la muestra analizada. La presencia de la realidad es amplia, pero no siempre se centra en la crítica a personajes concretos. Es frecuente la denuncia política a través de la caricatura de personajes relevantes en ese ámbito, pero compite con celebridades del deporte y del espectáculo, entre otros. En nuestra muestra, el humor político no fue el contenido más frecuente.

Aún prevaleciendo el entretenimiento, se advierte la presencia de dos funciones en esta clase de humor, la función crítica y la función de distanciamiento con respecto a la realidad y el predominio de la deformación y la ambigüedad en la identidad de las voces. La frecuencia de aparición de personajes conocidos parece relacionarse más con la viabilidad del humor que con la presencia mayor o menor de dichos personajes en los medios. 
La calidad de las imitaciones produce equívocos, aparentemente no buscados, que han favorecido la aparición de una variante del sketch, a la que podríamos denominar fake sketch o «sketches de falsa llamada telefónica», donde el humorista, valiéndose de su capacidad de imitación, se hace pasar por una figura pública y provoca una situación real en la que lleva a engaño a otra figura pública, y a veces a parte de la audiencia.

Del mismo modo, se detecta la presencia de micro sketches en contenidos como retransmisiones deportivas. Denominamos a esta figura sketch integrado, pues la pieza cómica se inserta en la retransmisión sin delimitar la frontera entre realidad y ficción.

\section{Bibliografía}

ABC.es (2016). «Rajoy no es el primero: otros presidentes sorprendidos por los imitadores». Recuperado de: http:/www.abc.es/recreo/abci-rajoy-no-primero-otros-Presidentessorprendidos-imitadores-201601211144_noticia.html (Fecha de acceso: 10/11/2016).

Albert, P. y Tudesq, A. J. (1981). Historia de la radio y la televisión. México: Fondo de cultura económica.

Álvarez, F. (2005). «Radiorrealidad» en ABC.es. Recuperado de: http://www.abc.es/ hemeroteca/historico-06-11-2005/abc/Comunicacion/radiorrealidad_612104672450. html (Fecha de acceso: 10/11/2016).

Bueno, G. (2000). Televisión: apariencia y verdad. Barcelona: Gedisa.

Bustos Sánchez, I. (2003). La voz. La técnica y la expresión. Barcelona: Paidotribo.

Cadena Ser (2016). «Un imitador se hace pasar por Puigdemont y consigue hablar con Rajoy». Recuperado de: http://cadenaser.com/ser/2016/01/21/politica/1453366363_929065.html (Fecha de acceso: 11/11/2016).

Catalina-García, B.; García Jiménez, A. y Montes Vozmediano, M. (2015). «Jóvenes y consumo de noticias a través de Internet y los medios sociales». En Historia y Comunicación Social Vol. 20, Núm. 2, pp. 601-619.

Checa, A. (1997). «Reflexiones sobre el presente de la radio en España». En IDUS. Depósito de investigación de la Universidad de Sevilla. Recuperado de: https://idus.us.es/xmlui/ bitstream/handle/11441/43956/Reflexiones $\% 20$ sobre $\% 20 \mathrm{el} \% 20$ presente $\% 20 \mathrm{de} \% 20$ la $\% 20$ Radio $\% 20$ en $\% 20$ Espa $\%$ C3\%B1a $\% 20 \% 281 \% 29$.pdf? sequence=1\&isAllowed=y (Fecha de acceso: 11/11/16).

Diez Puertas, E. (2003). Narrativa audiovisual. La escritura radiofónica y televisiva. Madrid: Universidad Camilo José Cela.

El Periódico (2016). «Rajoy se confiesa ante un falso Puigdemont en una broma de una radio: 'Tengo la agenda muy libre'». Recuperado de: http://www.elperiodico.com/es/ noticias/politica/llamada-puigdemont-rajoy-4833044 (Fecha de acceso: 11/11/2016).

Estudio General de Medios (2016). Audiencia de Internet en el EGM. Recuperado de: http:// www.aimc.es/-Audiencia-de-Internet-en-el-EGM-.html (Fecha de acceso: 11/11/2016)

Estupiñán, O. (2010). La narrativa de los realities show en España: Representaciones de la hiperrealidad e hiperficcionalidad (Tesis doctoral inédita) Departamento de Comunicación Audiovisual y Publicidad II. Madrid: Universidad Complutense de Madrid.

Europa Press (2016). «Ciudadanos y PSOE critican que se banalice la relación entre el Gobierno y la Generalitat». Recuperado de El Mundo: http://www.elmundo.es/espana/20 16/01/21/56a0c3eb46163f280b8b4627.html (Fecha de acceso: 11/11/2016). 
Garcia, F. (et alt.) (1997). Radio fin de siglo. Sevilla: Ediciones Trípode (comunicación e imagen).

Gómez Martínez, P. J. y Casal Valbuena, M. (2015). «Falso documental y Retórica: una explicación desde el contenido y sus efectos». En Opción, Año 31, No. Especial 1, pp. 324-337.

Guarinos Galán, V. (2009). Manual de narrativa radiofónica. Madrid: Síntesis.

Izquierdo, A. J. (2006). «Procedimientos de restauración del sentido ordinario de la realidad: un estudio de las secuencias de revelación de las bromas de cámara oculta». En Reis. Núm.106, pp. 103-137.

La Vanguardia (2016). «Rajoy es objeto de una broma radiofónica: un falso Puigdemont logra una cita para verse la semana que viene». Recuperado de: http://www.lavanguardia. com/politica/20160121/301566837283/rajoy-broma-radiofonica-puigdemont-falso.html (Fecha de acceso: 11/11/2016).

López, D. (2014). "Análisis de géneros radiofónicos de ficción: Adaptación literaria y sketch». En Radioecos. Recuperado de: https://radioecosblog.wordpress.com/david/ analisis-de-generos-radiofonicos-de-ficcion-adaptacion-literaria-y-sketch/ (Fecha de consulta 11/11/2016).

Martín Rojo, L. (2007). «Discursos en guerra. Crónicas y humor político en torno a la ocupación de Irak». En Discurso \& Sociedad, Vol. 1, Núm. 4, pp. 575-603.

Martínez-Costa, Ma P. y Moreno, E. (Coord.). (2004). Programación radiofónica. Arte y técnica del diálogo entre la radio y su audiencia. Lima/Barcelona: Hurope.

Puente, A. (2016). La otra cara de la broma: Rajoy, dispuesto a verse con Puigdemont a pesar de que el PP defiende no hablar con independentistas. Recuperado de: http://www. eldiario.es/rastreador/AUDIO-catalana-engana-Rajoy-Puigdemont_6_476012400.html (Fecha de acceso: 11/11/2016).

Rodero, E. y Soengas, X. (2010). Ficción radiofónica. Madrid: Instituto Oficial de Televisión (IORTV).

Roger, M. (2016). «Rajoy, a un falso Puigdemont: 'Le llamo el lunes 25 y fijamos una fecha'». Recuperado de: http://ccaa.elpais.com/ccaa/2016/01/21/catalunya/1453365433_242882. html (Fecha de acceso: 11/11/2016).

Salaverría, R. (2003). «Convergencia de los medios». En Chasqui. Revista latinoamericana de Comunicación, Núm. 7, pp. 32-39.

Villacañas, B. (2003). «Brendan Kennelly's Cromwell: black comedy as exorcism». En Estudios ingleses de la Universidad Complutense. Madrid: Biblioteca Complutense, Servicio de Publicaciones. 